\title{
Manifestações oculares da COVID-19: Uma revisão narrativa de literatura
}

\author{
Ocular manifestations of COVID-19: A narrative literature review \\ Manifestaciones oculares de COVID-19: Una revisión de la literatura narrativa
}

Recebido: 11/05/2021 | Revisado: 18/05/2021 | Aceito: 22/05/2021 | Publicado: 08/06/2021

\author{
Tânia Gisela Biberg-Salum \\ ORCID: https://orcid.org/0000-0003-3317-2848 \\ Universidade Estadual de Mato Grosso do Sul, Brasil \\ E-mail: tsalum@uol.com.br \\ Ana Luiza Ceolin Lyrio \\ ORCID: https://orcid.org/0000-0002-8822-3297 \\ Universidade Estadual de Mato Grosso do Sul, Brasil \\ E-mail: lyrioana@hotmail.com \\ Pedro Henrique Canale \\ ORCID: https://orcid.org/0000-0001-5426-2389 \\ Universidade Estadual de Mato Grosso do Sul, Brasil \\ E-mail: pedro_canale@hotmail.com
}

\begin{abstract}
Resumo
Objetivos: Este artigo tem como objetivo analisar as manifestações oftalmológicas da COVID-19 descritas na literatura, assim como a duração dos sintomas e a relação temporal entre o início das manifestações oculares e das manifestações sistêmicas. Métodos: É uma revisão narrativa de literatura, utilizando os seguintes descritores: infecção por coronavírus, betacoronavírus, COVID-19, doenças oculares e manifestações oculares, sendo utilizadas as bases eletrônicas LILACS e MEDLINE, buscando artigos publicados entre os meses de maio a agosto de 2020. Resultados: A pesquisa inicial identificou 824 artigos, sendo que 14 cumpriam os critérios de inclusão. Dos casos relatados de ceratoconjuntivite, as manifestações oculares mais descritas são a hiperemia conjuntival, monocular ou binocular, e o edema de pálpebra. Outros sintomas que podem aparecer com frequência são a diplopia, sensação de corpo estranho, visão turva e a presença de secreções aquosas e viscosas. Conclusão: Conclui-se que a principal manifestação ocular associada à presença do SARS-CoV-2 é a hiperemia conjuntival, com duração variável entre 2 e 30 dias.
\end{abstract}

Palavras-chave: Coronavírus; Pandemia; Oftalmopatias; SARS-CoV-2; Conjuntivite.

\begin{abstract}
Objectives: This paper aims to analyse current data in the literature about the clinical manifestations of COVID-19 in ophthalmology, the duration of the symptoms, and correlate them with the systemic manifestations. Methods: It is a narrative literature review, using the following search terms: coronavirus infection, betacoronavirus, COVID-19, ocular disease, and ocular manifestation, using the electronic databases LILACS and MEDLINE, searching for articles published between May to August 2020. Results: The initial search identified 824 articles and 14 attended the inclusion criteria. Of the reported cases of keratoconjunctivitis, the most described ocular manifestations are conjunctival hyperemia, monocular and binocular, and eyelid edema. Other symptoms that can appear frequently are diplopia and binocular diplopia; foreign body sensation, blurred vision, and presence of watery and viscous secretion. Conclusion: In conclusion, the main ocular manifestation associated with the presence of SARS-CoV-2 is conjunctival hyperemia, with a variable duration between 2 and 30 days.
\end{abstract}

Keywords: Coronavírus; Pandemics; Eye diseases; SARS-CoV-2; Conjunctivitis.

\section{Resumen}

Objetivos: Este artículo visa analizar los datos existentes en la literatura sobre las manifestaciones clínicas del COVID19 en oftalmología, la duración de los síntomas y correlacionarlos con manifestaciones sistémicas. Métodos: Es una revisión narrativa de la literatura, utilizando los siguientes descriptores: infección por coronavirus, betacoronavirus, COVID-19, enfermedades oculares y manifestaciones oculares, utilizando las bases de datos electrónicas LILACS y MEDLINE, buscando artículos publicados entre los meses de mayo a agosto de 2020. Resultados: La investigación inicial identificó 824 artículos, 14 de los cuales cumplieron con los criterios de inclusión. De los casos notificados de queratoconjuntivitis, las manifestaciones oculares descritas con mayor frecuencia son hiperemia conjuntival, monocular o binocular y edema palpebral. Otros síntomas que pueden aparecer con frecuencia son diplopía, sensación de cuerpo extraño, visión borrosa y presencia de secreciones acuosas y viscosas. Conclúsion: Se concluye que la principal 
manifestación ocular asociada a la presencia de SARS-CoV-2 es la hiperemia conjuntival, con una duración variable entre 2 y 30 días.

Palabras clave: Coronavirus; Pandemias; Oftalmopatías; SARS-CoV-2; Conjuntivitis.

\section{Introdução}

No final de 2019 foi identificado um novo Coronavírus causador de síndromes respiratórias em Wuhan, China, que foi posteriormente denominado de SARS-CoV-2 e a doença a ele associada, nominada COVID-19. Apresenta período de incubação médio estimado entre 5 e 6 dias, podendo variar entre 0 a 14 dias (Brasil, 2020).

A principal fonte de transmissão dessa nova cepa viral é o contato com indivíduos sintomáticos, principalmente pelas mãos não higienizadas, e pelo contato com gotículas respiratórias de pacientes infectados (Ministério da Saúde, 2020). Atualmente, o padrão-ouro para o diagnóstico laboratorial no Brasil é a técnica do RT-PCR (Pinto et. al., 2020). Ademais, essa técnica também permitiu evidenciar a presença de partículas virais do SARS-CoV-2 na superfície ocular através da coleta de amostras do swab conjuntival, sugerindo que os olhos sejam mais um sítio de infecção pelo vírus (Emparan et. al., 2020).

A maioria dos pacientes com COVID-19 não apresenta sintomas, contudo, o curso clínico pode variar de assintomático completo à pneumonia e síndrome do desconforto respiratório agudo grave e outras complicações sistêmicas. O risco de desenvolver uma forma grave da doença é maior nos indivíduos idosos e naqueles com comorbidades subjacentes (Bezerra Santo, Monteiro \& Muto, 2020). As manifestações oftalmológicas demonstradas em animais são a conjuntivite aguda, uveíte anterior, retinite e neurite óptica, enquanto nos seres humanos há destaque para a conjuntivite aguda, embora, na literatura, ainda sejam escassos os estudos sobre esta temática (Scalinci \& Trovato Battagliola, 2020).

Há diversos esquemas terapêuticos descritos para COVID-19, sendo que os principais, sistemicamente utilizados são antivirais e antibióticos. Quanto à terapia tópica, destinada às manifestações oculares, descrevem-se o uso de compressas frias nas pálpebras para aliviar os sintomas; o uso de colírios, tanto de lágrimas artificiais, quanto associações com antivirais, até o uso de gel antiviral (Salducci \& La Torre, 2020).

Desta forma, o objetivo deste estudo é analisar as manifestações oftalmológicas da COVID-19 descritas na literatura, assim como a duração dos sintomas e a relação temporal entre o início das manifestações oculares e das manifestações sistêmicas.

\section{Metodologia}

O presente estudo apresenta-se como uma pesquisa de abordagem qualitativa, do tipo pesquisa bibliográfica e trata-se de uma revisão narrativa da literatura. Tal tipo de estudo, qualitativo, caracteriza-se por destacar a relevância da interpretação dos autores acerca do fenômeno em análise (Pereira, Shitsuka, Parreira, \& Shitsuka, 2018), além de fundamentar-se na interdependência dinâmica entre o sujeito e o objeto, sendo que os dados não são inertes e neutros e sim possuidores de significados e relações (Chizzotti, 2017).

Para além de sua abordagem, esta pesquisa bibliográfica demonstra ser apropriada para o contexto ao qual se propõe, pois favorece o aporte de novos e ampliados conhecimentos sobre uma determinada temática, permitindo a reflexão sobre o estado da arte do assunto em pauta (Toledo \& Rodrigues, 2017).

Ressalta-se que, para o desenvolvimento deste estudo exploratório, os autores formularam uma pergunta que norteou a investigação bibliográfica: "Quais manifestações oftalmológicas causadas pela COVID-19, em pacientes adultos, têm sido descritas na literatura vigente?". Para contemplar essa inquietude, planejou-se a busca por referências nas bibliotecas virtuais ao longo do mês de agosto do ano de 2020. 
A busca pelos artigos foi realizada por dois revisores nas bases de dados MEDLINE (Medical Literature Analysis and Retrieval System Online), via PubMeb e Literatura Latino-Americana e do Caribe em Ciências da Saúde (LILACS).

Termos controlados, extraídos dos Descritores em Ciências da Saúde (DeCS), foram combinados por meio dos operadores booleanos OR e AND para busca dos artigos no LILACS, como segue: (“Coronavirus Infections” OR "Betacoronavirus”) AND ("Eye disease" OR "Eye Manifestations"). Para busca no PubMed foram utilizados os termos extraídos do Medical Subject Headings (MeSH) e combinados da seguinte forma: (("Eye Manifestations"[Majr]) OR "Eye Diseases"[Mesh]) AND "COVID19" [Supplementary Concept]. Para a exclusão das publicações duplicadas foi utilizado o aplicativo Mendeley®.

Os critérios de elegibilidade para a seleção dos artigos foram: pacientes adultos (18 anos ou mais), diagnóstico de COVID19 por exames laboratoriais de biologia molecular tipo RT-PCR ou exames imunológicos do tipo ensaio enzimático (EnzymeLinked Immunosorbent Assay - ELISA) ou Imunocromatografia (teste rápido) para detecção de anticorpos IgM e IgG ou Imunoensaio por Eletroquimioluminescência (ECLIA) ou por pesquisa de antígenos: resultado reagente para SARS-CoV-2 pelo método de Imunocromatografia para detecção de antígeno, presença de manifestações oculares e data de publicação entre os meses de maio a agosto de 2020. Foram excluídos os artigos que não apresentavam resumo online, aqueles que não informaram a idade/faixa etária e/ou os dados clínicos dos pacientes, como também os artigos que abordavam estudos com animais. Foram aceitos todos os tipos de delineamento de estudos.

Dois revisores extraíram os dados dos artigos incluídos, dos quais foram analisados: identificação dos artigos (título, autoria, periódico, data de publicação); objetivos; características metodológicas (critérios de inclusão e exclusão); dados clínicos dos participantes (sexo, idade, diagnóstico, sintomas, duração dos sintomas); principais resultados e conclusões.

\section{Resultados}

Na pesquisa inicial foram encontrados 824 artigos (194 no MEDLINE e 630 no LILACS). Após análise de título e resumo online e removidos os artigos duplicados foram selecionados 47 artigos para a revisão. Desses, 14 artigos cumpriam os critérios de inclusão, conforme a Figura 1. Nenhuma restrição de idioma foi usada, os artigos em outros idiomas além de inglês, espanhol, português e francês foram traduzidos em três plataformas online diferentes: Google Translator®, DocTranslator® and DeepL®. 
Research, Society and Development, v. 10, n. 6, e51310615979, 2021

(CC BY 4.0) | ISSN 2525-3409 | DOI: http://dx.doi.org/10.33448/rsd-v10i6.15979

Figura 1 - Seleção dos Artigos.

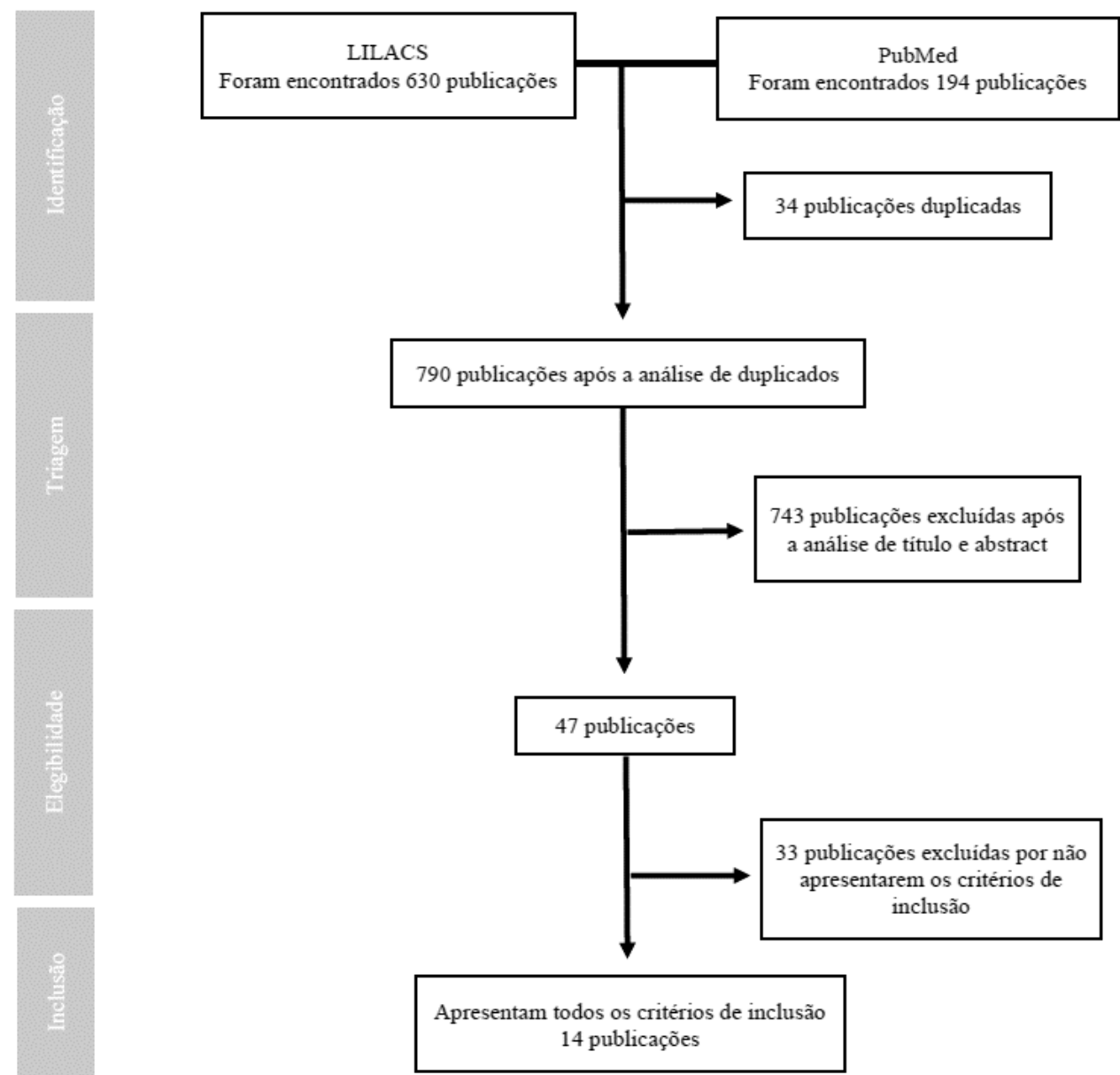

Fonte: Autores.

Os principais motivos da exclusão dos artigos foram por não apresentar a idade/faixa etária da população abordada, população pediátrica, diagnóstico clínico ou por exames de imagem, por não apresentar descrição das manifestações oculares, por não se enquadrar no período de publicação entre maio e agosto de 2020 ou não apresentar resumo disponível online.

Dos 14 artigos analisados, dois tratavam-se de revisões sistemáticas, um estudo de delineamento transversal e 11 relatos de caso, conforme a Tabela 1. 
Tabela 1 - Caracterização dos estudos quanto ao tipo de estudo, manifestações oculares, duração dos sintomas e relação com as manifestações sistêmicas.

\begin{tabular}{|c|c|c|c|c|c|c|}
\hline Autor & $\begin{array}{l}\text { Tipo de } \\
\text { Estudo }\end{array}$ & $\begin{array}{l}\text { Idade dos } \\
\text { Pacientes }\end{array}$ & Sexo & Manifestações Oculares & $\begin{array}{c}\text { Dura } \\
\text { ção } \\
\text { dos } \\
\text { Sinto } \\
\text { mas }\end{array}$ & $\begin{array}{c}\text { Relação temporal } \\
\text { entre as } \\
\text { manifestações } \\
\text { oculares e as } \\
\text { manifestações } \\
\text { sistêmicas }\end{array}$ \\
\hline $\begin{array}{l}\text { Selvaraj } \\
\text { et al. }\end{array}$ & $\begin{array}{l}\text { Relato de } \\
\text { Caso }\end{array}$ & 50 anos & Feminino & $\begin{array}{c}\text { Perda aguda da visão monocular } \\
\text { direita. }\end{array}$ & - & $\begin{array}{l}\text { Início ocular após } \\
\text { início sistêmico. }\end{array}$ \\
\hline Pascual- & Relato de & 60 anos & Feminino & Diplopia & 1 mês & $\begin{array}{c}\text { Início ocular } \\
\text { simultâneo ao início } \\
\text { sistêmico. }\end{array}$ \\
\hline Goñi et al. & Caso & 35 anos & Feminino & Diplopia, oftalmoparesia. & - & $\begin{array}{l}\text { Início ocular anterior } \\
\text { ao início sistêmico. }\end{array}$ \\
\hline Guo et al. & $\begin{array}{l}\text { Relato de } \\
\text { Caso }\end{array}$ & 53 anos & Masculino & $\begin{array}{l}\text { Dor, hiperemia, edema, secreção } \\
\text { aquosa e pequena quantidade de } \\
\text { secreção viscosa. Olho direito com } \\
\text { hiperemia e edema. }\end{array}$ & 7 dias & $\begin{array}{l}\text { Início ocular após } \\
\text { início sistêmico. }\end{array}$ \\
\hline $\begin{array}{l}\text { Nayak et } \\
\text { al. }\end{array}$ & $\begin{array}{l}\text { Relato de } \\
\text { Caso }\end{array}$ & 65 anos & Masculino & $\begin{array}{l}\text { Hiperemia conjuntival do olho } \\
\text { direito e congestão conjuntival. }\end{array}$ & $\begin{array}{c}14 \\
\text { dias }\end{array}$ & $\begin{array}{l}\text { Início ocular após } \\
\text { início sistêmico. }\end{array}$ \\
\hline $\begin{array}{c}\text { Fernández } \\
- \\
\text { Domíngue } \\
\text { z et al. }\end{array}$ & $\begin{array}{l}\text { Relato de } \\
\text { Caso }\end{array}$ & 74 anos & Feminino & Visão turva. & 5 dias & $\begin{array}{l}\text { Início ocular após } \\
\text { início sistêmico. }\end{array}$ \\
\hline $\begin{array}{c}\text { Álvarez et } \\
\text { al. }\end{array}$ & $\begin{array}{l}\text { Relato de } \\
\text { Caso }\end{array}$ & 48 anos & Masculino & Diplopia binocular. & 5 dias & $\begin{array}{l}\text { Início ocular após } \\
\text { início sistêmico. }\end{array}$ \\
\hline $\begin{array}{l}\text { Chen et } \\
\text { al. }\end{array}$ & $\begin{array}{l}\text { Relato de } \\
\text { Caso }\end{array}$ & 30 anos & Masculino & $\begin{array}{l}\text { Hiperemia, sensação de corpo } \\
\text { estranho e secreção lacrimal em } \\
\text { ambos os olhos. }\end{array}$ & 6 dias & $\begin{array}{l}\text { Início ocular após } \\
\text { início sistêmico. }\end{array}$ \\
\hline $\begin{array}{l}\text { Aiello et } \\
\text { al. }\end{array}$ & $\begin{array}{c}\text { Revisão } \\
\text { Sistemática }\end{array}$ & $\begin{array}{l}\text { Média de } \\
\text { idade entre } \\
25,7-72,4 \\
\text { anos }\end{array}$ & - & Conjuntivite & - & - \\
\hline
\end{tabular}




\begin{tabular}{|c|c|c|c|c|c|c|}
\hline $\begin{array}{l}\text { Daruich et } \\
\text { al. }\end{array}$ & $\begin{array}{l}\text { Relato de } \\
\text { Caso }\end{array}$ & 27 anos & Masculino & $\begin{array}{l}\text { Sensação de corpo estranho, } \\
\text { hiperemia conjuntival e edema na } \\
\text { pálpebra unilateral. }\end{array}$ & $\begin{array}{c}11 \\
\text { dias }\end{array}$ & $\begin{array}{l}\text { Início ocular anterior } \\
\text { ao início sistêmico. }\end{array}$ \\
\hline $\begin{array}{l}\text { Salducci } \\
\text { et al. }\end{array}$ & $\begin{array}{l}\text { Relato de } \\
\text { Caso }\end{array}$ & 72 anos & Masculino & $\begin{array}{l}\text { Conjuntivite, irritação, fotofobia e } \\
\text { secreção aquosa bilateral. }\end{array}$ & 7 dias & $\begin{array}{l}\text { Ausência de sintomas } \\
\text { sistêmicos. }\end{array}$ \\
\hline $\begin{array}{l}\text { Khavandi } \\
\text { et al. }\end{array}$ & $\begin{array}{l}\text { Relato de } \\
\text { Caso }\end{array}$ & 65 anos & Masculino & Conjuntivite viral & & $\begin{array}{l}\text { Início ocular anterior } \\
\text { ao início sistêmico. }\end{array}$ \\
\hline $\begin{array}{l}\text { Latalska } \\
\text { et al. }\end{array}$ & $\begin{array}{c}\text { Revisão } \\
\text { Sistemática }\end{array}$ & $\begin{array}{l}\text { Média de } \\
\text { idade: } 35 \text { - } \\
\quad 65\end{array}$ & - & $\begin{array}{l}\text { Conjuntivite, hiperemia conjuntival, } \\
\text { sensação de corpo estranho, dor } \\
\text { ocular, visão borrada, olho seco, } \\
\text { prurido e quemose. }\end{array}$ & - & - \\
\hline $\begin{array}{l}\text { Lantos et } \\
\text { al. }\end{array}$ & $\begin{array}{l}\text { Relato de } \\
\text { Caso }\end{array}$ & 36 anos & Homem & $\begin{array}{c}\text { Olho esquerdo caído, visão borrada, } \\
\text { oftalmoparesia progressiva, ataxia, } \\
\text { hiporeflexia - Miller Fisher } \\
\text { Syndrome. }\end{array}$ & 4 dias & $\begin{array}{l}\text { Início ocular anterior } \\
\text { ao início sistêmico. }\end{array}$ \\
\hline $\begin{array}{l}\text { Abrishami } \\
\text { et al. }\end{array}$ & $\begin{array}{c}\text { Estudo } \\
\text { Transversal }\end{array}$ & $\begin{array}{c}23-96 \\
\text { anos }\end{array}$ & $\begin{array}{c}77 \text { part. } \\
\text { Sexo } \\
\text { Masculino e } \\
65 \text { part. } \\
\text { Sexo } \\
\text { Feminino }\end{array}$ & Hiperemia conjuntival e quemose. & - & - \\
\hline
\end{tabular}

Fonte: Autores.

\section{Discussão}

Esta é uma revisão narrativa que visa investigar e analisar os dados existentes na literatura sobre a natureza das manifestações clínicas oculares da COVID-19, destacando o tempo de duração dos sinais e sintomas, além de correlacionar o momento de início das manifestações sistêmicas com as oftalmológicas e a presença ou não do vírus no swab conjuntival, visando contribuir para melhora da prática profissional sobre o assunto.

Os resultados sintetizados apontam para uma maior prevalência de manifestações oculares em pacientes do sexo masculino (54,2\%). Além disso, a faixa etária mais atingida é a dos idosos, sendo de 62,6 anos a idade média apontada nos estudos, variando entre 23 a 76 anos. Somando-se a isso, tem-se que 19,7\% dos pacientes recebiam cuidados intensivos (Abrishami et al., 2020).

As principais manifestações sistêmicas associadas aos sintomas oculares são a febre, a tosse seca e mialgia (Salducci \& La Torre, 2020; Abrishami et. al., 2020; Lantos, Strauss \& Lin 2020; Latalska \& Mackiewicz, 2020). A relação temporal referente ao momento de início desses sintomas demonstrou ser amplamente variável, podendo ser a conjuntivite o primeiro sintoma da doença, aparecendo horas ou até mesmo dias antes dos demais sintomas típicos de COVID-19, enquanto em outros casos relatados, as manifestações oftalmológicas se desenvolveram durante o período de internação (Chen et. al., 2020; Daruich 
\& Bremond-Gignac 2020; Lantos et. al., 2020; Khavandi, Tabibzadeh, Naderan \& Shoar, 2020). É válido ressaltar que também foi descrita ocorrência isolada dos sintomas oculares (Salducci \& La Torre, 2020).

Dos casos relatados, cuja apresentação do quadro ocular foi a ceratoconjuntivite, as manifestações clínicas que mais aparecem são a hiperemia conjuntival (Fernández-Domínguez,Ameijide-Sanluis, Garcia-Cabo \& Mateos, 2020; Guo et. al, 2020; Nayak, Poddar, Panigrahi, Tripathy \& Mishra, 2020), que se apresentou tanto de forma monocular quanto binocular, e o edema de pálpebra (Abrishami et.al., 2020; Daruich \& Bremond-Gignac, 2020; Guo et. al., 2020). Outros sintomas citados frequentemente são a diplopia (Álvarez, Cuervo \& Menéndez, 2020; Guo et. al, 2020), sensação de corpo estranho (Daruich \& Bremond-Gignac 2020; Selvaraj, Sacchetti \& Dapaah-Afriyie 2020), a visão turva e a presença de secreções aquosas e/ou mucosas (Lantos, et. al., 2020; Fernández-Domínguez, et. al., 2020; Selvaraj, et. al., 2020). Sintomas e sinais como fotofobia, oftalmoparesia, quemoses, olho seco e perda aguda da visão também figuraram nos relatos (Abrishami, et. al., 2020; Lantos, et. al., 2020; Pascual-Goñi, et. al., 2020; Salducci \& La Torre, 2020; Selvaraj, et. al, 2020). Ademais, um estudo apontou para a participação do SARS-CoV-2 como possível agente desencadeante de síndromes raras, como a Síndrome de Muller Fisher (Lantos, et. al., 2020).

Quanto a duração das manifestações oculares, os relatos quanto a diploplia apresentam períodos que oscilam entre 5 e 30 dias, enquanto a perda da visão, que pode ser monocular ou binocular, pode durar cerca de 2 dias, assim como a visão turva, que pode perdurar por até 5 dias (Fernández-Domínguez, et. al, 2020; Pascual-Goñi, et. al, 2020). Os quadros de conjuntivite persistiram de 6 a 14 dias, apresentando-se de forma uni ou bilateral (Chen et. al., 2020; Nayak, et. al, 2020). A partir de tais informações pode-se inferir pela variedade de apresentações, sem ainda concluir-se por uma linearidade quanto ao intervalo de tempo do acometimento ou mesmo a forma de manifestação clínica dos aspectos oftalmológicos relacionados à COVID-19.

Em se tratando das condutas terapêuticas específicas para as manifestações oculares, tratamentos tópicos à base de colírios de oxifloxacina, cloridrato de levofloxacina, colírio de ribavirina, fluorometolona, colírios lubrificantes/lágrimas artificias foram os mais frequentemente citados (Chen, et. al, 2020; Guo, et. al., 2020; Khavandi, et. al., 2020; Nayak, et. al., 2020; Scalinci \& Trovato Battagliola, 2020). Os estudos também descrevem a associação de tratamento sistêmico como adjuvante, considerando o uso de antivirais como o Lopinavir associado ao Ritonavir , o Umifenovir, o Oseltamivir e o gel de Ganciclovir , além da hidroxicloroquina e sua associação com azitromicina . A utilização de compressas frias oculares também foi uma técnica sugerida para o alívio dos sintomas (Álvarez, et. al., 2020; Férnandez-Domíngues, et. al., 2020; Lantos, et. al., 2020; Pascual-Goñi, et. al., 2020).

No que concerne aos testes diagnósticos, a literatura analisada demonstrou não haver correlação entre a ocorrência das manifestações oculares e o resultado positivo de um RT-PCR de secreção conjuntiva, conjecturando que, possivelmente, esse fato se dê ou pela baixa carga viral presente na secreção conjuntival, ou por coleta ou manuseio inadequado de amostras ou ainda a baixa sensibilidade do teste para o RNA SARS-CoV-2, que tem apresentado variância entre 50 a $60 \%$ (Aiello et. al, 2020; Latalska \& Mackiewicz, 2020).

\section{Conclusão}

Sendo assim, partindo dos dados investigados e aqui compilados, conclui-se que a principal manifestação ocular associada à presença do SARS-CoV-2 é a hiperemia conjuntival, sendo que a duração, a depender da especificidade do sinal/sintoma, apresenta-se com intervalo variável, oscilando entre 2 e 30 dias, e que, considerando-se a correlação entre o momento de início do quadro ocular e do quadro sistêmico, não há resultado constante, podendo acontecer antes, depois ou de forma simultânea, ainda que os relatos de casos descrevam, de forma mais frequente, o início dos sinais/sintomas oculares depois do início do quadro sistêmico. 
Considera-se ser de fundamental importância, para o profissional médico e os demais profissionais que atuam no cuidado à saúde relativo à COVID-19, o conhecimento acerca dos dados epidemiológicos, as manifestações oftalmológicas e tratamentos que possam contribuir para a prática clínica nesta especialidade. Dada a escassez, na comunidade científica, de publicações que tratem sobre o referido tema, o presente estudo almeja contribuir para que a oftalmologia tenha ampliado referencial teórico disponível para auxiliar os profissionais da área no manejo da atual pandemia.

Ademais, diante das novas variantes do vírus da COVID-19 no país, recomenda-se suscitar futuros trabalhos abrangendo novos achados e um volume maior de conteúdo científico, a fim de prover maiores níveis de evidência, melhorando a assistência em saúde e minimizando os impactos da pandemia.

\section{Referências}

Abrishami, M., Tohidinezhad, F., Daneshvar, R., Omidtabrizi, A., Amini, M., Sedaghat, A., Amini, S., Reihani, H., Allahyari, A., Seddigh-Shamsi, M., Tayyebi, M., Naderi, H., Bojdy, A., Khodashahi, R., \& Eslami, S. (2020). Ocular Manifestations of Hospitalized Patients with COVID-19 in Northeast of Iran. Ocular immunology and inflammation, 28(5), 739-744. https://doi.org/10.1080/09273948.2020.1773868

Aiello, F., Gallo Afflitto, G., Mancino, R., Li, J. O., Cesareo, M., Giannini, C., \& Nucci, C. (2020). Coronavirus disease 2019 (SARS-CoV-2) and colonization of ocular tissues and secretions: a systematic review. Eye (London, England), 34(7), 1206-1211. https://doi.org/10.1038/s41433-020-0926-9

Álvarez, Á.I. \& Cuervo, C. \& Menéndez, Santiago. (2020). SARS-CoV-2 infection associated with diplopia and anti-acetylcholine receptor antibodies. Neurología (English Edition). 35. 10.1016/j.nrleng.2020.04.003.

Bezerra, D. R. C., Santo, F. H. E., Monteiro, J. K. M. F., \& Muto, T. S. (2020). The vulnerables in the COVID-19 period: an integrative literature review. Research, Society and Development, 2525-3409, http://dx.doi.org/10.33448/rsd-v9i10.8860

Brasil, Ministério da Saúde (2020). Protocolo de manejo clínico da Covid-19 na Atenção Especializada. https://bvsms.saude.gov.br/bvs/publicacoes/manejo_clinico_covid-19_atencao_especializada.pdf

Brasil, Ministério da Saúde (2020). Protocolo de manejo clínico do coronavírus (COVID-19) na atenção primária à saúde. https://saude.rs.gov.br/upload/arquivos/202004/14140606-4-ms-protocolomanejo-aps-ver07abril.pdf

Chen, L., Liu, M., Zhang, Z., Qiao, K., Huang, T., Chen, M., Xin, N., Huang, Z., Liu, L., Zhang, G., \& Wang, J. (2020). Ocular manifestations of a hospitalised patient with confirmed 2019 novel coronavirus disease. The British journal of ophthalmology, 104(6), 748-751. https://doi.org/10.1136/bjophthalmol-2020316304

Chizzotti, A. (2017). Pesquisa em ciências humanas e sociais (12a ed.). São Paulo: Cortez.

Daruich, A., Martin, D., \& Bremond-Gignac, D. (2020). Ocular manifestation as first sign of Coronavirus Disease 2019 (COVID-19): Interest of telemedicine during the pandemic context. Journal francais d'ophtalmologie, 43(5), 389-391. https://doi.org/10.1016/j.jfo.2020.04.002

Emparan, Juan Pablo Olivares-de, Sardi-Correa, Carolina, López-Ulloa, Juan Alberto, Viteri-Soria, Jaime, Penniecook, Jason A., Jimenez-Román, Jesús, \& Lansingh, Van C. (2020). COVID-19 and the eye: how much do we really know? A best evidence review. Arquivos Brasileiros de Oftalmologia, 83(3), 250261. Epub May 29, 2020.https://doi.org/10.5935/0004-2749.20200067

Fernández-Domínguez, J., Ameijide-Sanluis, E., García-Cabo, C., García-Rodríguez, R., \& Mateos, V. (2020). Miller-Fisher-like syndrome related to SARSCoV-2 infection (COVID 19). Journal of neurology, 267(9), 2495-2496. https://doi.org/10.1007/s00415-020-09912-2

Guo, D., Xia, J., Wang, Y., Zhang, X., Shen, Y., \& Tong, J. P. (2020). Relapsing viral keratoconjunctivitis in COVID-19: a case report. Virology journal, 17(1), 97. https://doi.org/10.1186/s12985-020-01370-6

Khavandi, S., Tabibzadeh, E., Naderan, M., \& Shoar, S. (2020). Corona virus disease-19 (COVID-19) presenting as conjunctivitis: atypically high-risk during a pandemic. Contact lens \& anterior eye: the journal of the British Contact Lens Association, 43(3), 211-212. https://doi.org/10.1016/j.clae.2020.04.010

Lantos, J. E., Strauss, S. B., \& Lin, E. (2020). COVID-19-Associated Miller Fisher Syndrome: MRI Findings. AJNR. American journal of neuroradiology, 41(7), 1184-1186. https://doi.org/10.3174/ajnr.A6609

Latalska, M., \& Mackiewicz, J. (2020). The implication of ocular manifestation of COVID-19 for medical staff and patients - systematic review. Annals of agricultural and environmental medicine: AAEM, 27(2), 165-170. https://doi.org/10.26444/aaem/122790

Nayak, B., Poddar, C., Panigrahi, M. K., Tripathy, S., \& Mishra, B. (2020). Manifestação tardia de conjuntivite folicular em paciente ventilado após pneumonia grave positiva para COVID-19. Revista indiana de oftalmologia, 68(8), 1675-1677. https://doi.org/10.4103/ijo.IJO_1682_20

Pascual-Goñi, E., Fortea, J., Martínez-Domeño, A., Rabella, N., Tecame, M., Gómez-Oliva, C., Querol, L., \& Gómez-Ansón, B. (2020). COVID-19-associated ophthalmoparesis and hypothalamic involvement. Neurology(R) neuroimmunology \& neuroinflammation, $7(5), \quad \mathrm{e} 823$. https://doi.org/10.1212/NXI.0000000000000823

Pereira A. S., Shitsuka, D. M., Parreira, F. J., \& Shitsuka, R. (2018). Metodologia da pesquisa científica. [free e-book]. Santa Maria/RS. Ed. UAB/NTE/UFSM.

Pinto, R. R. S., Souza, H. M., Cunha, M. A., Melo, M. M. C., Teixeira C. V. P., Moura, I. El. S., Firmo, W. C. A. (2020). General aspects of laboratory techniques for the diagnosis of COVID-19. Research, Society and Development, 2525-3409, http://dx.doi.org/10.33448/rsd-v9i9.7845 
Research, Society and Development, v. 10, n. 6, e51310615979, 2021

(CC BY 4.0) | ISSN 2525-3409 | DOI: http://dx.doi.org/10.33448/rsd-v10i6.15979

Salducci, M., \& La Torre, G. (2020). COVID-19 emergency in the cruise's ship: a case report of conjunctivitis. La Clinica terapeutica, 171(3), e189-e191. https://doi.org/10.7417/CT.2020.2212

Scalinci, S. Z., \& Trovato Battagliola, E. (2020). Conjunctivitis can be the only presenting sign and symptom of COVID-19. IDCases, 20 , e00774. https://doi.org/10.1016/j.idcr.2020.e00774

Selvaraj, V., Sacchetti, D., Finn, A., \& Dapaah-Afriyie, K. (2020). Acute Vision Loss in a Patient with COVID-19. Rhode Island medical journal (2013), 103(6), $37-38$.

Toledo, Juliane Alvarez de, \& Rodrigues, Marisa Cosenza. (2017). Teoria da mente em adultos: uma revisão narrativa da literatura. Boletim - Academia Paulista de Psicologia, 37(92), 139-156. http://pepsic.bvsalud.org/scielo.php?script=sci_arttext\&pid=S1415-711X2017000100011\&lng=pt\&tlng=pt. 